\title{
The fate of polar trace organic compounds in the hyporheic zone
}

Jonas L. Schaper, Wiebke Seher, Gunnar Nützmann, Anke Putschew, Martin Jekel, Jörg Lewandowski@ https://orcid.org/0000-0001-5278-129X

DOI

https://doi.org/10.1016/j.watres.2018.04.040

\section{Original publication date}

16 April 2018 (Available online)

\section{Document version}

Accepted manuscript

Published in

Water Research

\section{Citation}

Schaper JL, Seher W, Nützmann G, Putschew A, Jekel M, Lewandowski J. The fate of polar trace organic compounds in the hyporheic zone. Water Research. 2018;140:158-66. 


\section{The fate of polar trace organic compounds in the hyporheic zone}

2 JONAS L. SCHAPER ${ }^{1,2} *$, WIEBKE SEHER ${ }^{1}$, GUNNAR NÜTZMANN ${ }^{1,3}$, ANKE PUTSCHEW $^{2}$, MARTIN JeKEL ${ }^{2}$ AND

3 JÖRG LEWANDOWSKI ${ }^{1,3}$

$4{ }^{1}$ Leibniz-Institute of Freshwater Ecology and Inland Fisheries, Department Ecohydrology, Müggelseedamm 310,

$5 \quad 12587$ Berlin, Germany

$6{ }^{2}$ Technical University of Berlin, Chair of Water Quality Engineering, Strasse des 17. Juni 135, 10623 Berlin,

$7 \quad$ Germany

$8 \quad{ }^{3}$ Humboldt University Berlin, Geography Department, Rudower Chaussee 16, 12489 Berlin, Germany

9

10 *corresponding author; schaper@igb-berlin.de, Leibniz-Institute of Freshwater Ecology and Inland Fisheries,

11 Department Ecohydrology, Müggelseedamm 310, 12587 Berlin, Germany 


\section{Abstract}

13 The hyporheic zone (HZ) is often considered to efficiently remove polar trace organic compounds

14 (TrOCs) from lotic systems, mitigating potential adverse effects of TrOCs on ecosystem functioning and

15 drinking water production. Predicting the fate of TrOCs in the hyporheic zone (HZ) is difficult as the in-

16 situ removal rate constants are not known and the biogeochemical factors as well as hydrological

17 conditions controlling the removal efficiency are not fully understood. To determine the in-situ removal

18 efficiency of the $\mathrm{HZ}$ for a variety of TrOCs as a function of the biogeochemical milieu, we conducted a

19 field study in an urban river near Berlin, Germany. Subsurface flow was studied by time series of

20 temperature depth profiles and the biogeochemical milieu of the HZ by concentration depth profiles.

21 These results, in conjunction with a 1D advection-dispersion transport model, were used to calculate first-

22 order removal rate constants of several polar TrOCs in the HZ. For the majority of TrOCs investigated,

23 removal rate constants were strongly dependent on redox conditions, with significantly higher removal

24 rates observed under predominantly suboxic (i.e. denitrifying) compared to anoxic (i.e. Fe and $\mathrm{Mn}$

25 reducing) conditions. Compared to previous studies on the fate of TrOCs in saturated sediments, half-lives

26 within oxic/suboxic sections of the $\mathrm{HZ}$ were relatively low, attributable to the site-specific characteristics

27 of the $\mathrm{HZ}$ in a stream dominated by wastewater treatment plant effluent. For nine out of thirteen

28 investigated TrOCs, concentrations decreased significantly in the $\mathrm{HZ}$ with relative removal percentages

29 ranging from $32 \%$ for primidone to $77 \%$ for gabapentin. For many TrOCs, removal efficiency decreased

30 drastically as redox conditions became anoxic. For the majority of compounds investigated here, the HZ

31 indeed acts as an efficient bioreactor that is capable of removing TrOCs along relatively short flow paths.

32 Depending on the TrOC, removal capacity may be enhanced by either increasing the magnitude of

33 groundwater-surface exchange fluxes, by increasing the total residence time in the $\mathrm{HZ}$ or the exposure

34 time to suboxic zones, respectively. 


\section{Keywords}

36 Pharmaceuticals, organic micropollutants, biotransformation, urban water cycle, removal efficiency 


\section{Introduction}

38 Trace organic compounds (TrOCs) derived from wastewater treatment plants (WWTP) are frequently

39 detected in surface waters in which they impair ecosystem functioning (Schwarzenbach et al., 2006) and

40 pose risks for drinking water production, especially in urban areas where water cycles might be partially

41 closed (Pal et al., 2014). The hyporheic zone (HZ), the interface between groundwater and surface water

42 in streams, has often been considered to efficiently remove TrOCs (Lewandowski et al., 2011). Depending

43 on the magnitude and direction of groundwater-surface water exchange and hyporheic exchange fluxes,

44 the HZ may contribute to the overall attenuation of TrOCs in streams (Riml et al., 2013; Writer et al.,

45 2013) and may act as a reactive barrier protecting groundwater from surface water pollution and vice

46 versa (Huntscha et al., 2013).

47 Quantitative information on the reactivity of TrOCs in saturated sediments, often expressed as first-order removal rate constants, predominantly originates from either laboratory experiments (Burke et al., 2014;

49 Li et al., 2015; Radke and Maier, 2014) or bank filtration studies (Henzler et al., 2014; Huntscha et al.,

50 2013). For many TrOCs, reported removal rate constants were found to be highly site- and experiment

51 specific and varied up to three orders of magnitude among different subsurface environments and

52 experimental setups (Greskowiak et al., 2017). It has further been shown that a variety of physical and

53 biogeochemical factors, such as temperature (Burke et al., 2014), redox conditions (Wiese et al., 2011),

54 concentrations of labile dissolved organic carbon (DOC) (Hoppe-Jones et al., 2012) and the abundance

55 and diversity of microorganisms (Bertelkamp et al., 2016) may influence the reactivity of TrOCs in

56 saturated sediments.

57 Compared to other subsurface environments, hyporheic zones are typically characterized by intense 58 microbial activity, diverse microbial communities and steep redox gradients (Boano et al., 2014). Field

59 investigations that link the fate of TrOCs to the distinct biogeochemical characteristics in the $\mathrm{HZ}$, are

60 widely lacking and thus, in-situ removal rate constants of TrOCs in the $\mathrm{HZ}$ are not known. Removal

61 efficiency of the $\mathrm{HZ}$ is generally not only a function of the removal rate constants and thus the 
62 biogeochemical milieu, but also of the time over which an attenuation reaction can take place (i.e. the

63 residence time). The spatial distribution of biogeochemical parameters, such as the ambient redox

64 potential in the HZ, is often tightly coupled to flow characteristics. Compared to bank filtration systems,

65 residence times in the $\mathrm{HZ}$ are usually much shorter. The in-situ interactions between transport timescales

66 in the $\mathrm{HZ}$ and the biogeochemical conditions that control the ambient reactivity of $\mathrm{TrOCs}$ in $\mathrm{HZ}$, (i.e. the

67 factors that govern the efficiency of the $\mathrm{HZ}$ in removing polar TrOCs) are poorly understood.

68 The present study had two aims: (i) providing in-situ first-order removal rate constants for several TrOCs

69 for the $\mathrm{HZ}$ of an urban lowland stream and (ii) determine the hydrological and biogeochemical factors that

70 limit the efficiency of the $\mathrm{HZ}$ in removing TrOCs. To this end, in-situ first-order removal rate constants

71 are determined for a variety of polar WWTP derived TrOCs under different redox conditions.

72 We hypothesize that in a river that is dominated by WWTP effluent removal rate constants in the

73 hyporheic zone substantially deviate from rates obtained in laboratory studies and bank filtration systems.

74 As reaction rates for many compounds are likely to be redox-dependent, reaction rates are expected to be

75 strongly controlled by redox conditions in the HZ. Consequently, removal efficiency is likely to depend on

76 both the extent of redox zones as well as on the magnitude of groundwater-surface exchange and

77 hyporheic exchange fluxes. 


\subsection{Site description}

80 River Erpe is an urban lowland river, located at the eastern edge of Berlin, Germany, that receives 81 between $60 \%$ and $80 \%$ of its discharge from the large municipal WWTP Münchehofe. A detailed 82 description of river morphology and general biogeochemical traits of River Erpe can be found elsewhere

83 (Lewandowski et al., 2011). The study site is located at Heidemühle (Lat: 52.478647, Long: 13.635146)

84 roughly $1 \mathrm{~km}$ downstream of the confluence of River Erpe and the WWTP Münchehofe effluent.

85 Streambed morphology at the field site was dominated by small dunes (crest height $<5 \mathrm{~cm}$ ) and 86 macrophyte cover during the study period was $<10 \%$. Streambed sediment characteristics were 87 determined from one $30 \mathrm{~cm}$ long core per station taken in close proximity $(<10 \mathrm{~cm})$ to the sampling 88 station using a hand auger $\left(9.0 \mathrm{~cm}\right.$ ID). Saturated hydraulic conductivities (K) at $10^{\circ} \mathrm{C}$, measured using a

89 KSAT device (UMS Munich), were found to be log-normally distributed with a mean value of $5.0 \times 10^{-5}$ $90 \mathrm{~m} \mathrm{~s}^{-1}$ and a standard deviation of $7.4 \times 10^{-5} \mathrm{~m} \mathrm{~s}^{-1}$. Mean sediment porosity calculated from oven dried 91 samples was $0.39 \pm 0.1$. Organic carbon content $\left(f_{o c}\right)$, determined by loss on ignition, ranged between 0.5 92 and 6 wt.\% and was found to be log-normally distributed with a mean value of $2.4 \pm 2.7$ wt.\%.

\section{$93 \quad 2.2$ Experimental setup overview and field investigation periods}

94 The experimental setup consisted of six stations (S1 - S6) located close to the south-eastern bank of River 95 Erpe (Figure 1a). Each sampling station was equipped with a ring enclosure (PVC pipes with a diameter 96 of $15 \mathrm{~cm}$ and a height of $32 \mathrm{~cm}$ ) which was inserted vertically into the sediment, with the top rim of the

97 pipe being level with the sediment surface. Concentrations of TrOCs in effluent-receiving streams are 98 typically variable in time as both concentrations of TrOCs in WWTP effluent itself as well as the relative 99 proportion of WWTP effluent to overall stream discharge may change on a sub-daily and daily basis 100 (Lewandowski et al., 2011). To overcome this challenge, we used dialysis chambers, also called peepers 101 (Hesslein, 1976), a passive sampling technique that integrates porewater solute concentrations over a time 
102 span of several days and thus allows the sampling of time integrated, quasi-steady-state concentration 103 depth profiles in the hyporheic zone. A detailed description on the functionality of peepers and their 104 applicability to sample TrOCs in the hyporheic zone is provided in the Supplementary Material (SM). 105 Between December $1^{\text {st }}$ and December $15^{\text {th }}, 2015$, peepers were used to collect porewater depth profiles in 106 the hyporheic zone (details below, section 2.4). To sample porewater both within the ring enclosure and 107 outside of the ring enclosure, one peeper was inserted into the sediment within the ring enclosure and one 108 inserted directly adjacent to the first one but outside of the ring enclosure (Figure $1 \mathrm{~b}$ ). Between December $1091^{\text {st }} 2015$ and April $15^{\text {th }}, 2016$, temperature probes (details below, section 2.3) were installed inside and 110 outside the ring enclosures. Vertical seepage flux inside the ring enclosure at S1, S2, S3, S4 and S6 as well 111 as outside ring enclosures at S3 was calculated from field temperature data measured between December $1121^{\text {st }} 2015$ and December $15^{\text {th }} 2015$. Due to a limited availability of temperature probes, vertical seepage 113 fluxes inside ring enclosure at S5 and outside ring enclosures at S1, S2, S4, S5 and S6 were calculated 114 from temperature data collected between January $5^{\text {th }}$ and April $15^{\text {th }} 2016$. This approach was justified as 115 (i) head gradients between river stage and the riparian aquifer were close to time invariant on timescales of 116 weeks and months and (ii) flux measurements made at the same station and peeper position between 117 December 2015 and April 2016 showed only little variation. A detailed summary of deployment periods 118 and the respective hydrodynamic conditions of the River Erpe between December 2015 and April 2016 119 can be found in the SM. The original purpose of the ring enclosures was to limit the influence of potential 120 horizontal subsurface flow in the hyporheic zone. However, flow investigations (sections 2.3.2 and 3.1) 121 did not indicate the presence of strong horizontal flow components outside the ring enclosures. As a result, 122 the same reactive transport model was used to evaluate concentration profiles both inside and outside the 123 ring enclosures. Stream stage, temperature and electrical conductivity (EC) were measured continuously 124 every 5 min between December $1^{\text {st }}, 2015$ and April 15 $5^{\text {th }}, 2016$ using a CTD Diver (Van Essen Instruments 125 B.V., Netherlands) installed in a stilling well (SW1, Figure 1a). Between February $8^{\text {th }}$ and April $15^{\text {th }}$, 126 additional head measurements were performed using a Pressure Diver (Van Essen Instruments B.V., 
127 Netherlands) in a second stilling well (SW2, Figure 1a) and a groundwater observation well (GW, Figure 128 1a). Head measurements were performed to gain general information on groundwater-surface water 129 interactions at the field site and qualitatively confirm the temperature based flux calculations (section 2.3). 130 Stream stage at SW2 during peeper deployment was inferred from correlations of stream stages at SW1 131 and SW2 between February $8^{\text {th }}$ and April $15^{\text {th }} 2016$ (Figure SM-02).

132 Daily variations of stream stage and EC showed a periodic saw-toothed pattern with stage and EC troughs 133 in the early morning and peaks around noon and in the afternoon (Figure SM-08). Water levels in the river 134 were consistently above groundwater level, even during early morning stage troughs. As a consequence, 135 the groundwater-surface water interactions were characterized by downwelling conditions, a finding 136 which is in qualitative agreement with the flux calculations in section 2.3. 
a)

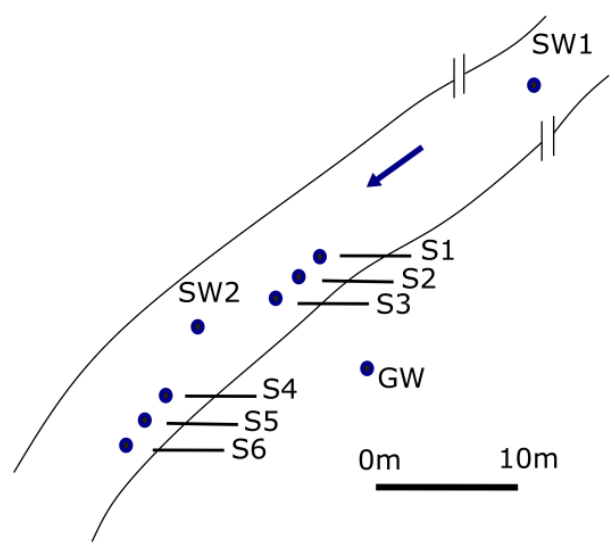

b)

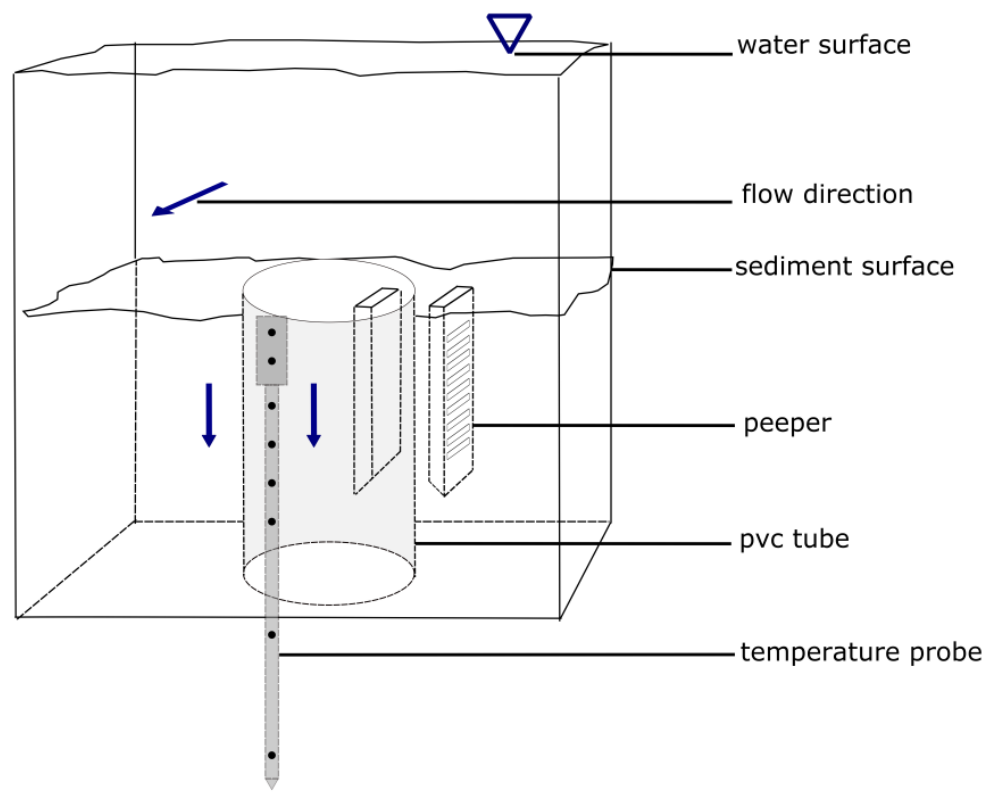

138

139

140

Figure 1 a) Study site with stations (S1 - S6) close to south-eastern bank of River Erpe. Surface water stilling well 1 (SW1) is approximately $100 \mathrm{~m}$ upstream of S1 while surface water stilling well 2 (SW2) is located between S3 and S4. A groundwater well (GW) with filter screen $1.5 \mathrm{~m}$ below the water table is located $5 \mathrm{~m}$ beside the river. b) Each of the six stations $\mathrm{S} 1-\mathrm{S} 6 \mathrm{consists}$ of a $32 \mathrm{~cm}$ long PVC pipe (ring enclosure) with its upper end being level with the sediment - water interface. Porewater samplers, so-called peepers, are placed next to each other inside and outside of the pipe, with the closed side of each peeper facing towards the PVC wall. Blue arrows indicate predominant flow directions.

\subsection{Calculation of vertical seepage fluxes and transport parameters}

\subsubsection{Measurements of temperature time series}

Temperature depth profiles were obtained using Multi Level Temperature Sticks (MLTS, UIT, Dresden), which are described in detail by Munz et al., (2011). In brief, MLTS sticks are polyoxymethylene sticks of a total length of $0.66 \mathrm{~m}$ and a diameter of $0.02 \mathrm{~m}$, which are equipped with eight TSIC-506 temperature sensors (accuracy $0.07{ }^{\circ} \mathrm{C}$ between $5{ }^{\circ} \mathrm{C}$ and $45^{\circ} \mathrm{C}$ ). The probes were placed vertically in the streambed, with the head of the temperature stick being level with the sediment surface. Temperature time series where obtained for sediment depths 7, 17, 22, 27, 32, 42 and $62 \mathrm{~cm}$. 
154 Vertical seepage flux estimates based on continuous time series of temperature depth profiles were 155 evaluated using the MATLAB code VFLUX 2.0 (Gordon et al., 2012). In brief, VFLUX 2.0 utilizes 156 dynamic harmonic regression (DHR) (Young et al., 1999) to extract amplitude damping ratios $\left(\mathrm{A}_{\mathrm{r}}\right)$ and 157 phase shifts $(\Delta \varphi)$ from two sinusoidal temperature time series measured at two different depths within the 158 stream sediment. DHR is a general case of the harmonic regression model in which the trigonometric 159 parameters describing the frequency components of the raw temperature time series may vary over time.

160 In the present study we used the combined $\mathrm{A}_{\mathrm{r}} \Delta \varphi$ method introduced by McCallum et al., (2012) to 161 calculate seepage fluxes.

162 Vertical seepage flux was evaluated at $2 \mathrm{~h}$ intervals between sensors in 7 and 17,17 and $27 \mathrm{~cm}$ depth 163 resulting in center-of-pair depths of 12 and $22 \mathrm{~cm}$, thus covering the depth range of porewater sampling. 164 Monte Carlo Analysis was performed using the "vfluxmc" function implemented in VFLUX 2.0. Mean 165 seepage flux rates were calculated by first averaging flux over depth and then averaging depth-integrated

166 fluxes over time. To minimize errors induced by DHR filtering, the first and last $24 \mathrm{~h}$ of flux results were 167 discarded. Since VFLUX provides Darcy fluxes (q), calculated flux rates were divided by the average 168 porosity to derive porewater velocities (v).

\subsubsection{Calculation of dispersion coefficients}

170 Based on the calculated porewater velocities, the respective effective hydrodynamic dispersion 171 coefficients $(D)$ were calculated via:

$$
D=\tau D_{m o l}+\alpha_{L} v
$$

174 in which $\tau$ denotes the tortuosity, $D_{m o l}$ the molecular diffusion coefficient, $v$ the porewater velocity and $\alpha_{\mathrm{L}}$ 175 the longitudinal dispersivity. Tortuosity $\tau$ was assumed to be 0.7 and $\alpha_{\mathrm{L}}$ was set to a tenth of the profile 176 length $(2 \mathrm{~cm})$. As $\mathrm{D}_{\mathrm{mol}}$ for the respective TrOCs are generally smaller than $10^{-9} \mathrm{~m}^{2} \mathrm{~s}^{-1}$ (Table SM-09) and 
177 porewater velocities measured in the present study were larger than $10^{-6} \mathrm{~m} \mathrm{~s}^{-1}$ (Table 1), the contribution

178 of $\mathrm{D}_{\text {mol }}$ to overall hydrodynamic dispersion coefficients was found to be negligible and thus molecular 179 diffusion was omitted in further calculations.

\section{$180 \quad 2.4$ Water sampling and analysis}

181 Deployed peepers (2.5 $\mathrm{cm} \times 9.5 \mathrm{~cm} \times 26.5 \mathrm{~h} \mathrm{x} \mathrm{w} \mathrm{x} \mathrm{1)} \mathrm{contained} 20$ chambers (approx. $10 \mathrm{~mL}$ of chamber 182 volume) in $1 \mathrm{~cm}$ increments. The chambers were filled with deionized water and covered with a 183 permeable membrane (polysulfon, $0.2 \mu \mathrm{m}$ HT Tuffryn 200, Pall Corporation). Prior to installation, peepers 184 were placed into oxygen free water to reduce oxygen input into streambed sediments. In contrast to 185 common sampling practice the peepers had to be inserted completely into the sediment, because first trials revealed a scouring around peepers if they were reaching into the overlying water. Thus, the peepers did not sample overlying water or the immediate sediment-water interface. Peeper chambers were sampled on site chamber by chamber immediately after recovery from the sediment using a needle and a $10 \mathrm{ml}$ syringe. Two $\mathrm{ml}$ of sampled porewater from each chamber were used for TrOC analysis, $2 \mathrm{ml}$ were used

190 for nitrate analysis and $3 \mathrm{ml}$ were used for major cation analysis. At SW1 an automatic water sampler 191 (model 3700, Teflon suction line, Teledyne ISCO, Lincoln, NE.) was deployed to take surface water 192 samples from December $1^{\text {st }}$ to December $15^{\text {th }}$. Approximately $350 \mathrm{ml}$ of surface water were collected 193 every hour from $20 \mathrm{~cm}$ below the water surface. Samples were combined in a flow proportional manner 194 based on stream stage derived hourly discharge, yielding a flow-weighted surface water sample for each 195 day during the peeper deployment period. Details on discharge measurements and the rating curve can be 196 found in the SM. Integrated water samples were used to measure time series of surface water $\mathrm{pH}$, TrOCs 197 and major cation concentrations. Details on sample filtering and storage are provided in the SM.

198 The TrOCs studied include the pharmaceuticals gabapentin (GAB), bezafibrate (BZF), diclofenac (DCF), venlafaxine (VLX), 4-formylaminoantipyrin (FAA), primidone (PRI), carbamazepine (CBZ), and metoprolol (MTP) as well as the artificial sweetener acesulfame (ACS) and two benzotriazoles (1H- 
TrOCs were measured via high performance liquid chromatography with tandem mass spectrometry 203 (HPLC-MS/MS) following a method established previously (Zietzschmann et al., 2016, 2015). Separation 204 was achieved on a XSelect HSS T3 HPLC column $(2.5 \mu \mathrm{m}$ particle size, $2.1 * 50 \mathrm{~mm}$, Waters, USA) 205 using a linear gradient (ultra pure water with 5 vol.-\% methanol (HPLC grade, J.T. Baker, USA) and 0.1 206 vol.-\% formic acid (HPLC grade, Sigma Aldrich, Germany) versus 100\% methanol). A TSQ Vantage 207 mass spectrometer (Thermo Fisher Scientific, USA) in ESI \pm modes was used for compound analysis. 208 Each TrOC was identified by the characteristic ratio of the peak areas of two fragments, which were 209 chosen according to the DAIOS database (Zweckverband Landeswasserversorgung, Stuttgart, Germany).

210 For TrOC quantification, deuterated internal standards (Toronto Research Chemicals, Canada) were used 211 in combination with the more abundant fragment ion. Calibration curves consisted of 9 standards that 212 ranged from 0.01 to $55 \mu \mathrm{g} / \mathrm{L}$ and were fitted using a weighted (1/x) linear regression model (coefficients 213 of determination, $\mathrm{R}^{2}$, were always > 0.99). Limits of quantification (LOQs, Table SM-01) were set to the 214 calibration level at which the less abundant fragment ion showed a signal to noise ratio of $\geq 3$. Data 215 evaluation was performed with Xcalibur 2.1 (Thermo Scientific). Additional details on the method are 216 provided in the SM.

217 Major cations and dissolved iron concentrations were determined via inductively coupled plasma optical 218 emission spectrometry (ICP-OES, ICP iCAP 6000series, Thermo Fisher). Nitrate-N was measured using a 219 continuous-flow-analyser (SAN ++, Skalar) after DIN EN ISO 13395. For each surface water sample, $\mathrm{pH}$ 220 was determined using a handheld $\mathrm{pH}$ meter, calibrated prior to each use (SenTix 41, WTW). 


\subsection{Modeling of removal rate constants}

222 The one-dimensional advection-dispersion transport equation including first-order decay was used to 223 calculate removal rate constants of TrOCs from porewater depth profiles. Assuming steady-state 224 conditions in a homogeneous medium, negligible retardation of TrOCs along flow paths and uniform flow 225 conditions, the 1D advective-dispersion transport equation can be written as:

$$
0=D \frac{d^{2} c}{d x^{2}}-v \frac{d c}{d x}-k c
$$

228 In which $v$ denotes the vertical porewater velocity $\left(\mathrm{m} \mathrm{s}^{-1}\right), D$ the effective hydrodynamic dispersion 229 coefficient $\left(\mathrm{m}^{2} \mathrm{~s}^{-1}\right)$ and $k$ the first-order removal rate constant $\left(\mathrm{s}^{-1}\right)$. Assuming that the solute concentration 230 is zero at infinite depth, the solution to Equation 4 can be written as:

$$
c(x)=c_{i n} e^{\frac{v-\sqrt{v^{2}+4 D k}}{2 D} x}
$$

233 In which $c_{i n}$ denotes an arbitrary input concertation at the sediment-water interface. Following 234 linearization, the exponent of Equation 3 was found by fitting a linear model to the concentration data 235 using the statistical software package R (R Core Team, 2016). Details on the derivation of the analytical 236 solution (Equation 3) and parameterization can be found in the SM. It should be noted that the removal 237 rate constant $(k)$, although mathematically treated as a first-order constant, actually represents a pseudo 238 constant, as it integrates a variety of attenuation processes. Removal rate constants were set to zero if the 239 relative removal within one profile or sub-profile was smaller than two times the associated standard 240 deviation. For calculation purposes, if the concentration of a compound in a depth profile was below the 241 LOQ, its concentration was set to the respective LOQ. Model assumptions are considered to be reasonably 242 well met as hydrological conditions and concentrations of TrOCs in the surface water remained relatively 
243 constant over the peeper sampling period (Figures SM-08 \& 11). Under these conditions peepers are likely 244 to sample quasi-steady-state concentration profiles in the HZ. As the majority of TrOCs investigated in the 245 present study are either neutral or negatively charged under ambient $\mathrm{pH}(\mathrm{pH}=7.7)$, electrostatic 246 interactions between TrOCs and hyporheic material are considered to be negligible. The investigated 247 TrOCs were further characterized by low $\log \mathrm{D}_{\text {ow }}$ values (Table SM-10) and thus retardation of TrOCs in 248 the HZ due to partitioning into sediment organic matter is likely to be small. Even for compounds that 249 show comparatively high $\log \mathrm{D}_{\text {ow }}$ values, such as CBZ and BTA, previous field studies found very low 250 retardation factors (Huntscha et al., 2013). Concentration time series of TrOCs in the surface water as well 251 as a detailed discussion of the relevance of sorption and the assumption of quasi-steady state are provided 252 in the SM. Since the study site was characterized by consistent downwelling (sections 2.2 and 3.1 ), 253 concentration data were not corrected for dilution with riparian groundwater. In order to compare removal 254 rate constants to literature values, compound half-lives were calculated according to:

$$
t_{1 / 2}=\frac{\ln (2)}{k}
$$




\section{Results and Discussion}

\section{$257 \quad 3.1$ Transport characteristics in the hyporheic zone}

258 The mean vertical porewater velocity (positive $=$ downward) ranged from $0.12 \mathrm{~m} \mathrm{~d}^{-1}$ inside $\mathrm{S} 4$ to $0.89 \mathrm{~m} \mathrm{~d}^{-}$

$259{ }^{1}$ inside S2 (Table 1). Fluxes at S2, S3, S4, S5 and S6 showed no difference with peeper position (i.e.

260 inside and outside ring enclosures), while the flux calculated outside S1 was only half the flux calculated

261 inside S1.

262 Table 1 Mean values \pm standard deviations of porewater velocities (v) for the different sampling stations and inside/outside ring 263 enclosures. Porewater velocities were calculated by dividing VFLUX derived Darcy velocities by sediment porosity.

\begin{tabular}{ccc}
\hline Station & \multicolumn{2}{c}{$\mathrm{v} \mathrm{m} \mathrm{d}^{-1}$} \\
& inside & outside \\
& $0.84 \pm 0.32$ & $0.36 \pm 0.13$ \\
S1 & $0.89 \pm 0.31$ & $0.83 \pm 0.34$ \\
S2 & $0.84 \pm 0.29$ & $0.85 \pm 0.30$ \\
S3 & $0.12 \pm 0.05$ & $0.25 \pm 0.08$ \\
S4 & $0.59 \pm 0.22$ & $0.65 \pm 0.24$ \\
S5 & $0.78 \pm 0.29$ & $0.81 \pm 0.30$ \\
S6 & &
\end{tabular}


265 The mean vertical seepage fluxes measured inside and outside the ring enclosures were well within the 266 range reported in similar studies (Fitzgerald et al., 2015; Gordon et al., 2012) and matched downward 267 seepage rates previously calculated for the same river stretch (Lewandowski et al., 2011). During the 268 entire investigation period (December 2015 - April 2016) flux estimates indicated positive (downward) 269 flux which is consistent with the general head gradient at the study site, indicating downward flux from 270 the river to the riparian aquifer (section 2.2).

271 Errors associated with the calculation of vertical seepage fluxes using the McCallum $\mathrm{A}_{\mathrm{r}} \Delta \varphi$ method mainly 272 result from non-ideal field conditions that violate model assumptions, such as non-uniform, non-steady 273 and multidimensional flow. As the ring enclosure only allows purely vertical and uniform flow, the model 274 assumptions of uniform one-dimensional flow fields are highly likely to be met for fluxes measured inside 275 ring enclosures. However, the flow field outside the ring enclosures could have been subjected to both 276 vertical and horizontal flow components. Additional model calculations indicated that horizontal 277 hyporheic exchange induced by small sand dunes and ripples was $<0.05 \mathrm{~m} \mathrm{~d}^{-1}$ (see SM for details). 278 Moreover, fluxes calculated inside ring enclosures resembled fluxes outside ring enclosures for all stations 279 but S1. It is thus unlikely that horizontal flow components significantly distorted the flow field outside 280 ring enclosures. Additional errors induced by non-steady flow conditions as well as non-ideal sensor 281 spacing and sensor accuracy were found to be of minor importance (see SM for detailed discussion).

282 We conclude that the vertical seepage fluxes calculated by the McCallum $\mathrm{A}_{\mathrm{r}} \Delta \varphi$ method are likely to 283 resemble the actual vertical seepage fluxes quite well. Consequently, differences between sites and peeper 284 positions result likely from sediment heterogeneity and the associated variability in hydraulic 285 conductivity. 


\subsection{Redox zonation in the HZ}

287 Nitrate concentrations were high in the surface water (median $\mathrm{NO}_{3}^{-}-\mathrm{N}$ concentration $3.5 \mathrm{mg} / \mathrm{L}$, Table SM288 07) and decreased rapidly within the streambed sediments. The only exception is the profile outside S2, in 289 which nitrate concentrations remained relatively constant. As nitrate was depleted, concentrations of total 290 dissolved iron and dissolved manganese $\left(\mathrm{Fe}_{\mathrm{tot}}, \mathrm{Mn}\right)$ increased (Figure SM-12). The depth ranges between 291 the sediment-water boundary and the depth at which nitrate was completely depleted as well as the range 292 between the depth at which $\mathrm{Mn}$ and $\mathrm{Fe}_{\text {tot }}$ concentrations increased and the lower end of the peeper were 293 considered to mark the extent of oxic to suboxic and anoxic redox conditions within the HZ (Figure SM-

294 12, Figure 2). The mean extent of oxic/suboxic and anoxic sub-sections in the $\mathrm{HZ}$ was $11 \pm 4 \mathrm{~cm}$ and $10 \pm$ $2953 \mathrm{~cm}$, respectively. The rapid consumption of surface water borne electron acceptors along relatively short 296 flow paths and hence the development of steep redox gradients at the surface water-streambed interface is 297 typical for hyporheic zones (Krause et al., 2017) and in agreement with previous studies on sediment 298 biogeochemistry conducted at River Erpe (Lewandowski et al., 2011).

299 The spatial extent of the redox zonation, i.e. the depth and steepness of the redoxcline, is generally a 300 function of both transport characteristics as well as biogeochemical parameters, such as the quality and 301 abundance of electron donors and acceptors, microbial turnover rates or the content of sediment organic matter. In previous field investigations higher exchange fluxes led to deeper oxygen penetration depths and later onset of denitrification (Harvey et al., 2013). The relatively steep redox gradients inside the ring

304 at S4 and S5 correspond qualitatively to lower seepage fluxes measured inside the ring enclosures at these stations. However, redox profiles inside the ring enclosures at S1 and S2 as well as redox profiles inside and outside S2, S5 and S6 were remarkably different, although vertical seepage rates were similar. Overall, no quantitative correlation was found between calculated vertical seepage flux rates and the extent of redox zones as shown in Figure 2. Since high resolution measurements of sedimentological characteristics of Erpe sediment were not available, it is difficult to differentiate between the combined effects of sedimentary and hydrological controls on redox zonation. The spatial variability of sediment 
311 organic matter $\left(f_{o c}\right)$ in the HZ of River Erpe, however, was relatively high (Figure SM-14). It therefore 312 seems likely that the spatial extent of redox zonation is not only a function of the magnitude of vertical 313 seepage flux but is also to a large extent controlled by the spatial distribution of sediment organic matter. 


\section{$314 \quad 3.3$ Reactivity of TrOCs in the HZ}

315 Removal rate constants were calculated over the entire profile range and for each redox zone (suboxic and 316 anoxic) shown in Figure 2. Note that the profile taken outside S2 was excluded as oxic conditions 317 prevailed and no denitrification was observed. Kruskal-Wallis tests demonstrated that for all compounds 318 but SMX, DTA, CBZ and VLX removal rate constants derived for suboxic conditions were significantly 319 larger $(\mathrm{p}<.05)$ than the ones calculated for anoxic conditions (Table 2). Consequently, for TrOCs that 320 showed redox-dependent attenuation, removal rate constants are only reported for the respective redox 321 conditions. Median half-lives obtained from oxic/suboxic conditions varied between $0.43 \mathrm{~d}$ for PRI and $3220.04 \mathrm{~d}$ for GAB (Table 2). General stability of TrOCs in the suboxic zone was in the order GAB $<$ ACS $\approx$ 323 BZF $<$ BTA $<$ DCF < MBT < PRI. Median half-lives for the same set of compounds calculated from 324 anoxic sections of the profile did not differ from zero or were even negative. Depth profiles of gabapentin, 325 associated model fits as well as the spatial extent of oxic/suboxic and anoxic zones are shown in Figure 2. 326 Depth profiles for the remaining TrOCs, individual removal rate constants calculated from every (sub-) 327 profile and a comparison of TrOC concentrations measured in the present study to concentrations 328 previously measured in River Erpe are provided in the SM. Due to analytical difficulties, removal rate constants and respective half-lives for ACS and VLX were only calculated from eight profiles. 


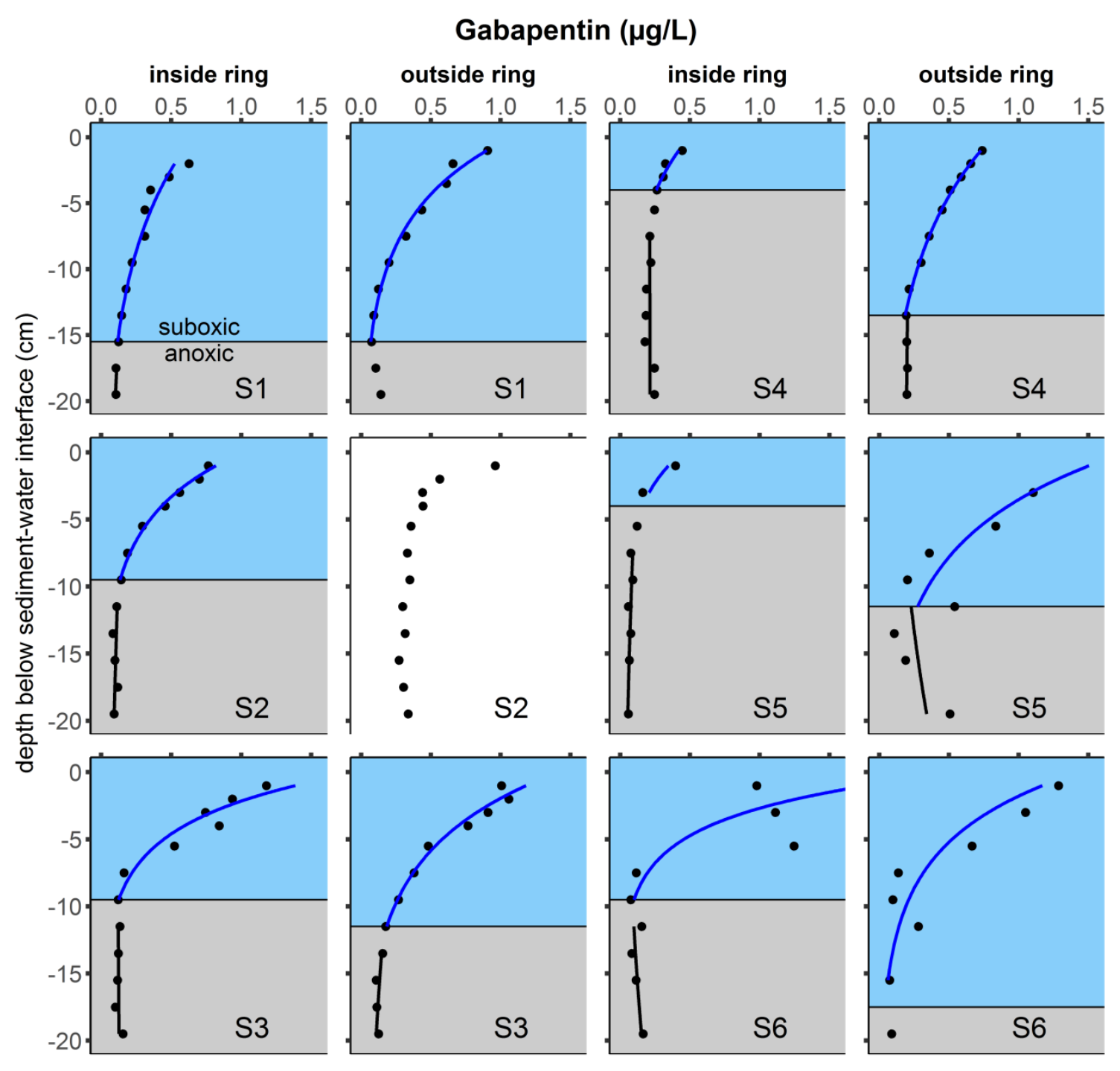

Figure 2 Equilibrium depth profiles of gabapentin (black dots) at the different sampling stations and inside/outside ring enclosures. The extent of oxic/suboxic and anoxic zones, as indicated by the presence of nitrate as well as dissolved $\mathrm{Mn}$ and $\mathrm{Fe}_{\mathrm{tot}}$, within the profiles is indicated with blue and grey shading, respectively. Modelled concentration profiles are shown for both oxic/suboxic and anoxic conditions (solid lines). Note that for outside of the ring enclosure at S2 no removal rate constants were calculated as redox condition remained oxic throughout the profile and no denitrification occurred. 
Table 2 Average removal percentages calculated over the entire profile, median half-lives and associated interquartile ranges (IQR) for all TrOCs investigated in this study. Kruskal-

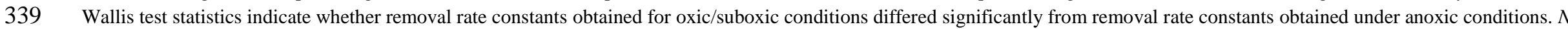
denotes the total number of profiles and $n$ the number of profiles in which removal was insignificant. According to relative removal (\%) and the redox dependency of removal rate constants, TrOCs were grouped into four groups: (i) removal > 15\%, significant redox influence on removal rate constants (ii) removal > 15\%, insignificant redox influence on removal rate constants (iii) removal $\leq 15 \%$, insignificant redox influence on removal rate constants and group (iv) compounds that showed ambiguous behaviour. Note that individual removal rate constants calculated from every (sub-) profile as well as median surface water concentrations of the investigated TrOCs are provided in the SM.

\begin{tabular}{|c|c|c|c|c|c|c|c|}
\hline \multirow[t]{2}{*}{ TrOC } & \multirow[t]{2}{*}{$\begin{array}{c}\text { Relative } \\
\text { removal } \\
(\%)\end{array}$} & \multicolumn{2}{|c|}{$\begin{array}{l}\text { Kruskal-Wallis test } \\
\text { statistics }\end{array}$} & \multicolumn{2}{|c|}{$\begin{array}{c}\text { Median } \mathrm{t}_{1 / 2} \pm \mathrm{IQR}_{1 / 2} \\
\text { (d) }\end{array}$} & \multicolumn{2}{|c|}{$n / N$} \\
\hline & & $\mathrm{p}$ - value & Chi square & oxic/suboxic & anoxic & oxic/suboxic & anoxic \\
\hline Gabapentin $^{(\mathrm{i})}(\mathrm{GAB})$ & $77 \pm 4$ & $<0.01$ & 13.6 & $0.04 \pm 0.05$ & $0.00 \pm 0.00$ & $0 / 11$ & $7 / 9$ \\
\hline Bezafibrate $^{(\mathrm{i})}(\mathrm{BZF})$ & $61 \pm 7$ & $<0.01$ & 12.5 & $0.05 \pm 0.06$ & $0.00 \pm 0.16$ & $0 / 11$ & $5 / 9$ \\
\hline Acesulfame $^{(\mathrm{i})}(\mathrm{ACS})$ & $66 \pm 7$ & $<0.01$ & 8.0 & $0.05 \pm 0.02$ & $-4.12 \pm 0.44$ & $1 / 7$ & $3 / 7$ \\
\hline Benzotriazole $^{(\mathrm{i})}$ (BTA) & $51 \pm 7$ & $<0.01$ & 14.8 & $0.09 \pm 0.13$ & $0.00 \pm 0.00$ & $0 / 11$ & $7 / 9$ \\
\hline Diclofenac $^{(\mathrm{i})}(\mathrm{DCF})$ & $36 \pm 9$ & $<0.01$ & 9.7 & $0.16 \pm 0.13$ & $0.00 \pm 0.00$ & $3 / 11$ & $8 / 9$ \\
\hline Methylbenzotriazole $^{(\mathrm{i})}(\mathrm{MBT})$ & $36 \pm 9$ & $<0.01$ & 13.3 & $0.18 \pm 0.26$ & $0.00 \pm 0.00$ & $1 / 11$ & $9 / 9$ \\
\hline Primidon $^{(\mathrm{i})}(\mathrm{PRI})$ & $32 \pm 10$ & $<0.01$ & 7.9 & $0.43 \pm 0.14$ & $0.00 \pm 0.00$ & $4 / 11$ & $9 / 9$ \\
\hline 4-Formylaminoantipyrin ${ }^{(\mathrm{iv})}$ (FAA) & $9 \pm 17$ & $<0.01$ & 6.5 & $0.00 \pm 0.15$ & $0.00 \pm 2.19$ & $6 / 11$ & $6 / 9$ \\
\hline \multirow[t]{2}{*}{ Metoprolol $^{(\mathrm{iv})}$ (MTP) } & $-6 \pm 17$ & 0.04 & 4.1 & $0.23 \pm 0.14$ & $0.00 \pm 0.43$ & $3 / 11$ & $4 / 9$ \\
\hline & & & & \multicolumn{2}{|c|}{ entire profile } & \multicolumn{2}{|c|}{ entire profile } \\
\hline Sulfamethoxazole $^{(\mathrm{ii})}$ (SMX) & $46 \pm 9$ & 0.08 & 3.1 & \multicolumn{2}{|c|}{$0.29 \pm 0.18$} & \multicolumn{2}{|c|}{$1 / 12$} \\
\hline Diatrizoic acid $^{(\mathrm{ii})}$ (DTA) & $33 \pm 10$ & 0.10 & 2.7 & \multicolumn{2}{|c|}{$0.32 \pm 0.22$} & \multicolumn{2}{|c|}{$3 / 12$} \\
\hline Venlafaxine $^{(i i i)}$ (VLX) & $14 \pm 12$ & 0.17 & 1.9 & \multicolumn{2}{|c|}{$0.00 \pm 0.74$} & \multicolumn{2}{|c|}{$5 / 8$} \\
\hline Carbamazepine $^{(\mathrm{iii})}(\mathrm{CBZ})$ & $15 \pm 12$ & 0.19 & 1.7 & \multicolumn{2}{|c|}{$0.00 \pm 0.49$} & \multicolumn{2}{|c|}{$8 / 12$} \\
\hline
\end{tabular}


344 Stability of TrOCs in the HZ varied widely with some TrOCs being readily attenuated in the HZ (i.e. 345 removal $>15 \%$ over the entire profile) and others being rather persistent (i.e. removal $\leq 15 \%$ ). Similar to 346 the findings of previous field and laboratory studies (Burke et al., 2014; Wiese et al., 2011), removal rate 347 constants for the majority of TrOCs investigated showed a strong dependence on redox conditions. Based 348 on the redox dependency as well as relative removal within the HZ, TrOCs were grouped into (i) 349 compounds that were removed by more than $15 \%$ and showed redox-dependent removal rate constants (ii) 350 compounds that were removed by more than $15 \%$ and showed redox-independent removal rate constants, 351 (iii) compounds that were removed by less than $15 \%$ and (iv) compounds that showed ambiguous 352 behavior within the sampled profiles.

353 Compounds in group i comprised ACS, GAB, BZF, BTA, MBT, DCF and PRI. Data on the fate of the 354 anticonvulsant gabapentin in saturated sediments is limited but a laboratory column study showed that 355 oxic conditions promote GAB removal (Hellauer et al., 2017). Acesulfame, an artificial sweetener, was 356 originally suggested to act as an ideal wastewater tracer (e.g., Engelhardt et al., 2013). More recent 357 studies, however, demonstrated as well as the present study that the compound undergoes redox358 dependent attenuation, with higher removal observed under oxic conditions (Burke et al., 2014; Regnery 359 et al., 2015). Reported half-lives for ACS under oxic/suboxic redox conditions range from $0.21 \mathrm{~d}$ to $4.2 \mathrm{~d}$, 360 exceeding the median half-life found in the $\mathrm{HZ}$ of River Erpe $(0.05 \mathrm{~d})$ by more than one order of 361 magnitude. The use of ACS as a tracer is therefore not recommended, especially if oxic to suboxic 362 conditions might occur along the flow path. Reported half-lives of bezafibrate, a lipid lowering agent, 363 range from $1.0 \mathrm{~d}$ in the transient storage zone of a natural river (Riml et al., 2013) to $1.9 \mathrm{~d}$ in a laboratory 364 flume study (Li et al., 2015) and are thus almost two orders of magnitude higher than the median half-life 365 calculated for oxic/suboxic conditions in the present study $(0.05 \mathrm{~d})$. The anti-corrosive agents 366 benzotriazole and its methyl analogue 5-methyl-1H-benzotriazole have both been shown to be relatively 367 stable in saturated sediments. (Liu et al., 2013), for instance, reported redox-dependent removal for MBT 368 and BTA in microcosms with half-lives of $60 \mathrm{~d}$ and $76 \mathrm{~d}$ for nitrate reducing conditions, while BTA was 
found to be persistent in a column study that used hyporheic sediment (Burke et al., 2014). These findings

370 are in contrast to the data reported in the present study showing that both BTA and MBT undergo rapid 371 removal within the HZ. Among all investigated TrOCs, BTA and MBT were the only ones for which 372 concentrations strongly correlated with each other $\left(\operatorname{adj} . \mathrm{R}^{2}=0.90\right.$, $\mathrm{p}$-vlaue $<0.01$ ), indicating that, in 373 principle, the same process seems to affect the removal of both compounds. A general redox dependency 374 of the removal of diclofenac, an analgesic, has been shown in both laboratory and field studies (Burke et 375 al., 2014; Wiese et al., 2011). Under oxic/suboxic conditions, reported half-lives ranged from $3 \mathrm{~d}$ to $36 \mathrm{~d}$ 376 within bank filtration settings (Henzler et al., 2014; Wiese et al., 2011). Shorter half-lives (0.13 d) were 377 observed in a column study (Burke et al., 2014), a value that agrees well with the half-life found in the 378 present study for oxic/suboxic conditions. Although the concentrations of primidone, an anticonvulsant, 379 did not decrease significantly in some of the oxic/suboxic sub-profiles (4 out of 11 profiles), overall mean 380 removal was found to be $32 \pm 10 \%$. This was not expected as previous studies found half-lives for PRI in 381 the order of several years (Regnery et al., 2015).

382 Compounds of group ii comprised the anti-bacterial agent sulfamethoxazole as well as the X-ray contrast agent diatrizoic acid. Both compounds were attenuated in the $\mathrm{HZ}$, but calculated removal rate constants did not depend on redox conditions. For SMX, this finding is in agreement with previous findings indicating its removal under both oxic and anoxic conditions (Baumgarten et al., 2011). In a laboratory flume study and during bank filtration, half-lives of $34 \mathrm{~d}$ and $22 \mathrm{~d}$ were reported for SMX respectively 387 (Henzler et al., 2014; Li et al., 2015) exceeding the median half-life found in this study (0.29 d) by roughly two orders of magnitude. Removal of DTA during wastewater treatment was reported (Haiß and 389 Kümmerer, 2006) but limited data on removal rate constants in natural sediments is available.

390 The anticonvulsant carbamazepine and the neuro-active compound venlafaxine (group iii) were found to 391 be rather stable in the $\mathrm{HZ}$ of River Erpe. CBZ was previously reported to be very persistent in saturated 392 sediments (Bertelkamp et al., 2014; Henzler et al., 2014). Although removal of CBZ has been described 393 for iron-reducing conditions (Wiese et al., 2011), ambient exposure times to such redox conditions in the 
394 present study were likely too short for the compound to be significantly removed. For VLX removal has 395 been demonstrated in the laboratory column study by Hellauer et al., (2017), but the compound was found 396 to be persistent in streams and during river bank filtration (Huntscha et al., 2013; Writer et al., 2013). It is 397 likely that residence times in the investigated section of the HZ were too short to achieve significant 398 attenuation for CBZ and VLX. Although median half-lives were zero for both compounds, in some 399 profiles concentrations of VLX and CBZ decreased significantly allowing the calculation of 400 comparatively low removal rate constants.

401 Similar inconsistent behaviour was also found for the compounds of group iv, the beta-blocker metoprolol 402 and 4-formylaminoantipyrin, a metabolite of the antipyretic drug dipyrone. Although MTP was persistent 403 in the transient storage zone of a natural river (Riml et al., 2013), half-lives of several hours were reported 404 in laboratory studies (Bertelkamp et al., 2014; Burke et al., 2014). Removal of 4-formylaminoantipyrin in 405 saturated sediments has been demonstrated in both laboratory and field studies with half-lives ranging 406 from 0.12 to 14 days (Burke et al., 2014; Wiese et al., 2011). Although overall removal for FAA and MTP 407 was insignificant, both showed positive removal during oxic/suboxic conditions and negative removal 408 rates (indicating concentrations increase) during anoxic conditions.

409 The order of relative stability of TrOCs encountered in the HZ of River Erpe partly differs from relative 410 stabilities described in other studies. For instance, CBZ was often found to be relatively more stable than 411 DCF (Burke et al., 2014; Wiese et al., 2011), which is in accordance with the findings of the present study. 412 In contrast, ACS has been found to be more stable than DCF (Burke et al., 2014; Regnery et al., 2015), 413 although in the present study DCF was more stable than ACS. Unsystematic findings with respect to 414 relative stabilities of TrOCs were mainly attributed to sediment heterogeneity and microbial community 415 diversity (Radke and Maier, 2014).

416 It should be further noted, that the calculation of removal rate constants in the present study is based on 417 field data collected under winter conditions with average hyporheic temperatures of $10^{\circ} \mathrm{C}$ (Figure SM-13). 418 Previous studies have shown that with increasing temperatures, removal rate constants increase (Burke et 
419 al., 2014). However, with increasing temperatures redox zonation may also shift upwards thus limiting 420 exposure time to oxic/suboxic redox conditions and rendering the HZ less efficient in removing 421 compounds that show preferred removal under oxic/suboxic conditions.

422 In summary, in-situ removal rate constants of the majority of TrOCs in the HZ of River Erpe are one or 423 even two orders of magnitude higher compared to removal rates reported in previous studies. We found 424 that even compounds that were previously regarded as very stable, such as BTA and PRI, are retained in 425 the HZ. As sorption is generally not regarded to considerably influence removal of polar TrOCs (see SM 426 for detailed discussion and $\log \mathrm{D}_{\mathrm{ow}}$ values), biotransformation is likely to be the dominant removal 427 mechanism for TrOCs in the HZ. Previous studies indicated that removal rate constants correlated 428 positively with microbial activity and TrOCs concentrations (Bertelkamp et al., 2016). The relatively high 429 removal rate constants in the HZ may thus be the results of site-specific characteristics of River Erpe, i.e. 430 high nutrient concentrations and high loads of TrOCs, high microbial activity in the upper centimetres of 431 the $\mathrm{HZ}$ as indicated by the steep redoxclines and the presence of a well-adapted microbial community. 


\section{Conclusion}

433 The present study provides in-situ removal rate constants of several polar TrOCs in the HZ of an urban

434 lowland stream. Compared to laboratory studies and bank filtration settings, removal rate constants of

435 TrOCs in the HZ were relatively high and thus HZs may efficiently remove TrOCs along short flow paths.

436 River restoration measures that explicitly aim at increasing hyporheic exchange in streams that are

437 dominated by WWTP effluent may thus improve whole-stream TrOCs removal and hence water quality.

438 We demonstrate that removal efficiency of the HZ is controlled by both residence times (i.e. advective

439 transport velocity and the magnitude of groundwater-surface water exchange fluxes) and the reactivity of

440 the respective TrOCs. For the majority of TrOCs, removal rate constants and thus removal efficiency of

441 the HZ were significantly higher under oxic/suboxic conditions than under anoxic conditions. When

442 predicting the fate of TrOCs in the $\mathrm{HZ}$ or assessing the relevance of the $\mathrm{HZ}$ with respect to whole-stream

443 TrOCs attenuation, future studies should therefore consider exposure times to ambient redox conditions

444 rather than overall residence time distributions in the HZ. For TrOCs that show redox-dependent

445 biotransformation, relative removal may be increased if exposure times to oxic/suboxic conditions are

446 enlarged.

447 The present study also suggests that high microbial activity promotes TrOCs removal. However, high 448 microbial activity also leads to steep redox gradients and, for many TrOCs, is thus expected to limit the 449 spatial extent of reactive zones in the HZ. More research is needed to understand the in-situ interactions 450 between exchange fluxes, microbial metabolism and the extent of favourable "reactive" zones in the HZ.

451 While we provide insights into the general fate of parent TrOCs in the HZ, future studies should also 452 include transformation products and thus aim at closing mass balances along flow paths. 


\section{References}

Baumgarten, B., Jährig, J., Reemtsma, T., Jekel, M., 2011. Long term laboratory column experiments to simulate bank filtration: Factors controlling removal of sulfamethoxazole. Water Res. 45, 211220. https://doi.org/10.1016/j.watres.2010.08.034

Bertelkamp, C., Reungoat, J., Cornelissen, E.R., Singhal, N., Reynisson, J., Cabo, A.J., van der Hoek, J.P., Verliefde, A.R.D., 2014. Sorption and biodegradation of organic micropollutants during river bank filtration: A laboratory column study. Water Res. 52, 231-241. https://doi.org/10.1016/j.watres.2013.10.068

Bertelkamp, C., van der Hoek, J.P., Schoutteten, K., Hulpiau, L., Vanhaecke, L., Vanden Bussche, J., Cabo, A.J., Callewaert, C., Boon, N., Löwenberg, J., Singhal, N., Verliefde, A.R.D., 2016. The effect of feed water dissolved organic carbon concentration and composition on organic micropollutant removal and microbial diversity in soil columns simulating river bank filtration. Chemosphere 144, 932-939. https://doi.org/10.1016/j.chemosphere.2015.09.017

Boano, F., Harvey, J.W., Marion, A., Packman, A.I., Revelli, R., Ridolfi, L., Wörman, A., 2014. Hyporheic flow and transport processes: Mechanisms, models, and biogeochemical implications. Rev. Geophys. 52, 603-679. https://doi.org/10.1002/2012RG000417

Burke, V., Greskowiak, J., Asmuß, T., Bremermann, R., Taute, T., Massmann, G., 2014. Temperature dependent redox zonation and attenuation of wastewater-derived organic micropollutants in the hyporheic zone. Sci. Total Environ. 482, 53-61. https://doi.org/10.1016/j.scitotenv.2014.02.098

Engelhardt, I., Prommer, H., Moore, C., Schulz, M., Schüth, C., Ternes, T.A., 2013. Suitability of temperature, hydraulic heads, and acesulfame to quantify wastewater-related fluxes in the hyporheic and riparian zone. Water Resour. Res. 49, 426-440. https://doi.org/10.1029/2012WR012604

Fitzgerald, A., Roy, J.W., Smith, J.E., 2015. Calculating discharge of phosphorus and nitrogen with groundwater base flow to a small urban stream reach. J. Hydrol. 528, 138-151. https://doi.org/10.1016/j.jhydrol.2015.06.038

Gordon, R.P., Lautz, L.K., Briggs, M.A., McKenzie, J.M., 2012. Automated calculation of vertical porewater flux from field temperature time series using the VFLUX method and computer program. J. Hydrol. 420, 142-158. https://doi.org/10.1016/j.jhydrol.2011.11.053

Greskowiak, J., Hamann, E., Burke, V., Massmann, G., 2017. The uncertainty of biodegradation rate constants of emerging organic compounds in soil and groundwater - A compilation of literature values for 82 substances. Water Res. 126, 122-133. https://doi.org/10.1016/j.watres.2017.09.017

Haiß, A., Kümmerer, K., 2006. Biodegradability of the X-ray contrast compound diatrizoic acid, identification of aerobic degradation products and effects against sewage sludge micro-organisms. Chemosphere 62, 294-302. https://doi.org/10.1016/j.chemosphere.2005.05.007

Harvey, J.W., Böhlke, J.K., Voytek, M.A., Scott, D., Tobias, C.R., 2013. Hyporheic zone denitrification: Controls on effective reaction depth and contribution to whole-stream mass balance: Scaling hyporheic flow controls on stream denitrification. Water Resour. Res. 49, 6298-6316. https://doi.org/10.1002/wrcr.20492

Hellauer, K., Mergel, D., Ruhl, A., Filter, J., Hübner, U., Jekel, M., Drewes, J., 2017. Advancing sequential managed aquifer recharge technology (SMART) using different intermediate oxidation processes. Water 9, 221. https://doi.org/10.3390/w9030221

Henzler, A.F., Greskowiak, J., Massmann, G., 2014. Modeling the fate of organic micropollutants during river bank filtration (Berlin, Germany). J. Contam. Hydrol. 156, 78-92. https://doi.org/10.1016/j.jconhyd.2013.10.005

Hesslein, R.H., 1976. An in situ sampler for close interval pore water studies. Limnol. Oceanogr. 21, 912 914. 
Hoppe-Jones, C., Dickenson, E.R.V., Drewes, J.E., 2012. The role of microbial adaptation and biodegradable dissolved organic carbon on the attenuation of trace organic chemicals during groundwater recharge. Sci. Total Environ. 437, 137-144. https://doi.org/10.1016/j.scitotenv.2012.08.009

Huntscha, S., Rodriguez Velosa, D.M., Schroth, M.H., Hollender, J., 2013. Degradation of polar organic micropollutants during riverbank filtration: Complementary results from spatiotemporal sampling and push-pull tests. Environ. Sci. Technol. 47, 11512-11521. https://doi.org/10.1021/es401802z

Krause, S., Lewandowski, J., Grimm, N.B., Hannah, D.M., Pinay, G., McDonald, K., Martí, E., Argerich, A., Pfister, L., Klaus, J., Battin, T., Larned, S.T., Schelker, J., Fleckenstein, J., Schmidt, C., Rivett, M.O., Watts, G., Sabater, F., Sorolla, A., Turk, V., 2017. Ecohydrological interfaces as hot spots of ecosystem processes. Water Resour. Res. 53, 6359-6376. https://doi.org/10.1002/2016WR019516

Lewandowski, J., Putschew, A., Schwesig, D., Neumann, C., Radke, M., 2011. Fate of organic micropollutants in the hyporheic zone of a eutrophic lowland stream: Results of a preliminary field study. Sci. Total Environ. 409, 1824-1835. https://doi.org/10.1016/j.scitotenv.2011.01.028

Li, Z., Sobek, A., Radke, M., 2015. Flume experiments to investigate the environmental fate of pharmaceuticals and their transformation products in streams. Environ. Sci. Technol. 49, 60096017. https://doi.org/10.1021/acs.est.5b00273

Liu, Y.-S., Ying, G.-G., Shareef, A., Kookana, R.S., 2013. Biodegradation of three selected benzotriazoles in aquifer materials under aerobic and anaerobic conditions. J. Contam. Hydrol. 151, 131-139. https://doi.org/10.1016/j.jconhyd.2013.05.006

McCallum, A.M., Andersen, M.S., Rau, G.C., Acworth, R.I., 2012. A 1-D analytical method for estimating surface water-groundwater interactions and effective thermal diffusivity using temperature time series. Water Resour. Res. 48. https://doi.org/10.1029/2012WR012007

Munz, M., Oswald, S.E., Schmidt, C., 2011. Sand box experiments to evaluate the influence of subsurface temperature probe design on temperature based water flux calculation. Hydrol. Earth Syst. Sci. 15, 3495-3510. https://doi.org/10.5194/hess-15-3495-2011

Pal, A., He, Y., Jekel, M., Reinhard, M., Gin, K.Y.-H., 2014. Emerging contaminants of public health significance as water quality indicator compounds in the urban water cycle. Environ. Int. 71, 4662. https://doi.org/10.1016/j.envint.2014.05.025

R Core Team, 2016. R: A language and environment for statistical computing. R Foundation for Statistical Computing, Vienna, Austria. URL https://www.R-project.org/.

Radke, M., Maier, M.P., 2014. Lessons learned from water/sediment-testing of pharmaceuticals. Water Res. 55, 63-73. https://doi.org/10.1016/j.watres.2014.02.012

Regnery, J., Wing, A.D., Alidina, M., Drewes, J.E., 2015. Biotransformation of trace organic chemicals during groundwater recharge: How useful are first-order rate constants? J. Contam. Hydrol. 179, 65-75. https://doi.org/10.1016/j.jconhyd.2015.05.008

Riml, J., Wörman, A., Kunkel, U., Radke, M., 2013. Evaluating the fate of six common pharmaceuticals using a reactive transport model: Insights from a stream tracer test. Sci. Total Environ. 458-460, 344-354. https://doi.org/10.1016/j.scitotenv.2013.03.077

Schwarzenbach, R.P., Escher, B.I., Fenner, K., Hofstetter, T.B., Johnson, A.C., von Gunten, U., Wehrli, B., 2006. The Challenge of Micropollutants in Aquatic Systems. Science 313, 1072-1077. https://doi.org/10.1126/science.1127291

Wiese, B., Massmann, G., Jekel, M., Heberer, T., Dünnbier, U., Orlikowski, D., Grützmacher, G., 2011. Removal kinetics of organic compounds and sum parameters under field conditions for managed aquifer recharge. Water Res. 45, 4939-4950. https://doi.org/10.1016/j.watres.2011.06.040

Writer, J.H., Antweiler, R.C., Ferrer, I., Ryan, J.N., Thurman, E.M., 2013. In-Stream Attenuation of Neuro-Active Pharmaceuticals and Their Metabolites. Environ. Sci. Technol. 47, 9781-9790. https://doi.org/10.1021/es402158t

Young, P.C., Pedregal, D.J., Tych, W., 1999. Dynamic harmonic regression. J. Forecast. 18, 369-394. 
Zietzschmann, F., Aschermann, G., Jekel, M., 2016. Comparing and modeling organic micro-pollutant adsorption onto powdered activated carbon in different drinking waters and WWTP effluents. Water Res. 102, 190-201. https://doi.org/10.1016/j.watres.2016.06.041

552

553

554

555

556

Zietzschmann, F., Mitchell, R.-L., Jekel, M., 2015. Impacts of ozonation on the competition between organic micro-pollutants and effluent organic matter in powdered activated carbon adsorption. Water Res. 84, 153-160. https://doi.org/10.1016/j.watres.2015.07.031 


\section{Acknowledgements}

558 This project has been conducted within the Research Training Group 'Urban Water Interfaces (UWI)'

559 (Project N6 "Retention of chemical compounds in hyporheic reactors of urban freshwater systems", GRK

560 2032/1), which is funded by the German Research Foundation (DFG). Furthermore, this project has also

561 received funding from the European Union's Horizon 2020 research and innovation programme under

562 grant agreement No. 641939 (HypoTRAIN). We thank T. Mehner and the participants of an IGB course in

563 Scientific Writing as well as three anonymous reviewers and the editor for comments and discussion on

564 earlier versions of this manuscript. 